\title{
Task allocation in production systems \\ - Measuring and Analysing Levels of Automation
}

\author{
Å.Fasth-Berglund*and J.Stahre \\ *Chalmers University of Technology, Production system, SE-41296 \\ (Tel: +46317723686; e-mail: asa.fasth@chalmers.se).
}

\begin{abstract}
Due to the paradigm of mass customisation, most of the tasks in final assembly are still performed by humans. Hence, the tasks are becoming more and more complex and the operators need not only physical but also cognitive support to perform their work. The paper discusses the need for a quantitative and easy-to-use method, which simultaneously considers physical and cognitive automation in order to choose and use the best suited Levels of Automation. A concept model used for task allocation is presented. It consists of a five-step main loop supported by other areas or relations were information is gathered to enable a decision in the main loop. The model is compared to Olders' et al. (1997) sixteen requirements for a task allocation method in order to prove its usefulness. The method has been developed, validated, and verified together with end-users (industry and novice users) in twenty companies to verify its practical ease-of-use.
\end{abstract}

Keywords: Cognitive Automation, task allocation, production, assembly, LoA, model

\section{INTRODUCTION}

In order to maintain sustainable manufacturing in an increasingly globalised industry, current traditions for design and usage of automation in assembly systems may not be adaptable to the needs and future challenges that companies are facing. Rapid changes of demands and requirements, both internal and external, frequently trigger plans for change in different manufacturing areas.

Smaller batches and shorter time limits for set-up between products are normal demands on the assembly systems caused by increasing numbers of product variants due to new industrial paradigms e.g. mass customisation. As a result, companies need increasingly flexible methods for assembling products and means to make assembly systems more proactive.

The relevance of a task allocation process is obvious, yet there is still lack of systematic methods and, more importantly, methods that can be applied to advanced technological systems (Older et al., 1997). Another problem with new methods and tools in the human factors area concerns their lack of uptake and use by system developers.

New methods must therefore be developed jointly with its users i.e. adaptable to be put in practice and the method must be validated within its planned area of use (Waterson et al., 2002, Older et al., 1997).

Numerous of attempts to create such methods have been made. This paper will not discuss the gaps fulfilled with the model. This is treated due to Olders' comparison of eighteen different methods for task allocation, which were developed between 1965 and 1992, and Fasths’ comparison with nine methods (Fasth, 2011), developed between 1990 and 2010.

This paper will compare Olders' requirements with the concept model to be able to confirm that this model could be used for task allocation in production systems.

\section{TASK ALLOCATION - towards a quantitative method}

A classical task allocation strategy from 1951 (the MABAMABA list) was proposed by Fitts (Fitts, 1951) is attempt to suggest allocation of tasks between humans and machines by treating them as system resources, each with different capabilities. Two examples, i.e. "Machines Are Better At performing repetitive and routine tasks" while "Men Are Better At improvising and using flexible procedures". At the time, this was a revolutionary thought causing a lot of debate.

Jordan (Jordan, 1963) argued whether you could actually compare man and machine; and that the two should be seen as complementary rather than conflicting resources when designing a man-machine system. Sheridan (Sheridan, 1995) suggested to "allocate to the human the tasks best suited to humans and allocate to the automation the task best suited to it. But, if tasks in which machines are better become automated and operators are still required to monitor the automation, maintaining full situation awareness (Endsley and Kiris, 1995, Endsley, 1997), we might lose more than we gain (Endsley, 1999). Fifty years after Fitts published his list, Hollnagel (Hollnagel, 2003b) argues that the machine (or automation) has been used for three main purposes over the years (which is in line with Fitts) i.e. to ensure more precise 
performance of a given function; to improve stability of performance by relieving people of repetitive and monotonous tasks; and to enable processes to be carried out faster and more efficiently. So, do Fitts' thoughts still prevail, or has research turned towards Jordan's argument?

The decision matrix suggested by Prince (Prince, 1985) was partly in line with Fitts in that some tasks were better performed by machines and some better by humans. But interestingly Prince also defined a set of tasks where the same task could and should be performed both by humans and by machines. Further, when there is no single allocation, the different resources need support from each other, which is in line with Jordan's argument. Hancock (Hancock and Chignell, 1992) argues that it is only when both human and machine can do the same task; the question of task allocation becomes an issue. In line with Jordan, previous research (Hancock and Chignell, 1992, Kantowitz and Sorkin, 1987, Hou et al., 1993, Sheridan, 2000) agrees that the task allocation should been seen as complementary between man and machine rather than dividing tasks solely to one resource. Suitable allocation of tasks between resourses (human operators and machines) and technique has to be made and must be able to be dynamically changeable over time. However, it is common that designers automate every subsystem which leads to an economic benefit for that subsystem but leaves the operator to manage the rest (Parasuraman and Wickens, 2008). Parasuraman et al. (Parasuraman et al., 2000) argues that automation design is not an exact science, however, neither does it belong in the realm of the creative arts, with successful design dependent upon the vision and brilliance of individual creative designers.

A problem related to 'MABA-MABA-oriented' methods is the simplicity e.g. "put your allocation problem into the method and the solution will emerge from the other end" (Dekker and Woods, 2002). The methods do not readily explain the cognitive actions for how and when to intervene, nor do they describe how to switch from level to level.

\section{EVALUATION STRATEGY for the concept model}

Older et al. (Older et al., 1997) presents fifteen requirements that a task allocation method should contain, divided into five areas:

\section{Design}

(II) Have a structured and systematic format (XVIII) Be cost effective and easy to use (XIX) Be consistent with existing tools and techniques in use

\section{Types of allocation}

(IV) Cover allocations to the humans and to the machines

(V) Cover allocations between humans, and examine different human roles

(XI) Incorporate the concept of dynamic allocations dependent on real time contingencies

\section{Approach}

(I) Be used early in the design process

(III) Allow iterative use, throughout the design process

(XII, XIII) Be easy to learn, usable, and require minimal training and support

(XII) Encourage participative use by various stakeholders, including the potential end users of the system (method)

(IX) Enable the users of the method to make informed choices

\section{Issues}

(VIII) Examine the content and quality of the human's job (VI) Specify decision criteria

(VII) Consider the trade-offs between the decision criteria

(X) Enable quantitative evaluations to be made of the alternative choices

\section{Coverage}

Examine the whole system, as well as individual tasks and roles

(XIV) Be applicable to complex environments and different systems within the same environment

(XV) Be adaptable (to different situations and tailored for unique applications)

Be capable of use in new and existing systems

The concept model will be discussed according to these five areas in following sections:

\subsection{Design}

DYNAMO++ was developed during 2007 and 2009 together with four companies. The methodology contains of twelve steps divided into four phases; pre-study, measurement, analysis, and implementation (Fasth et. al. 2008). The methodology is built partly on other methods such as Value Stream Mapping (VSM) (Liker, 2004), Hierarchical Task Analysis (HTA) (Stanton et al., 2005), Annette and Duncan, 1967) and Levels of Automation (LoA)-taxonomy (Frohm et al., 2008). This applies to Olders' requirement :(XIX) Be consistent with existing tools and techniques in use

A further development of the methodology was made in 2010 (Fasth and Stahre, 2010), resulting in a concept model, presented in fig. 1. The aim of the concept model was to visualize relations between different areas and actions within a company when redesigning a system in terms of levels of automation through task allocation. Furthermore, to have a clear view why to change the system in order to avoid overor under- automated systems. Additionally, the model also considers the cognitive LoA, the information system (here called the Level of Information - LoI) to and from the operators and different Levels of Competence (LoC) in the operator group. This applies to Olders' requirement (II) Have a structured and systematic format (applies for the concept model as well)

The DYNAMO++ methodology and the concept model have been used in more than twenty companies by experts and novice users between 2007-2013, some results from these cases is brought up in following sections. The advantage 
with the model is that it is built up in modules. Depending on the companies triggers for changing the system the different modules could be used on a more or less detailed level. This applies to Olders' requirement: (XVIII) Be cost effective and easy to use.

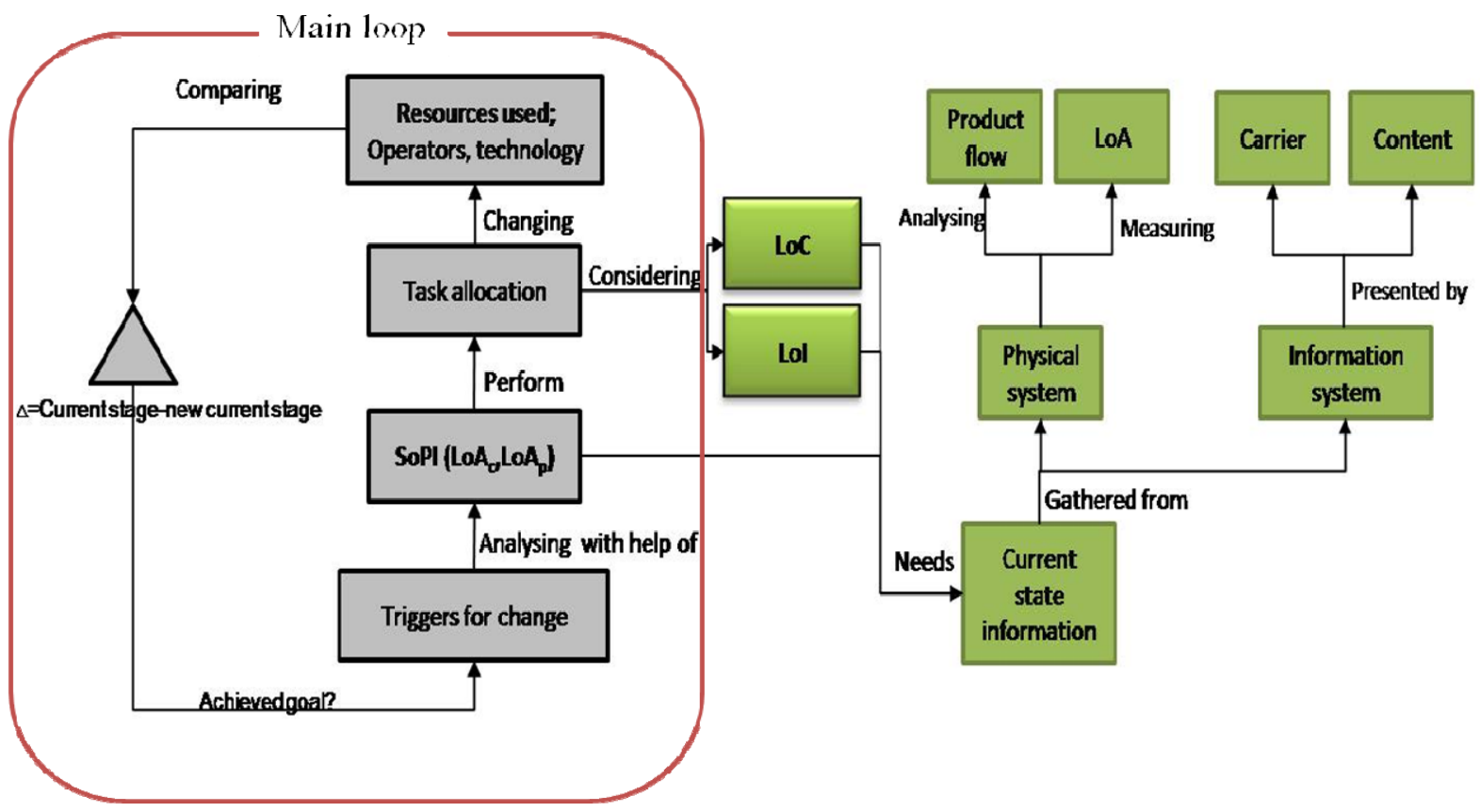

Fig. 1 Concept model, further developed from DYNAMO++ (Fasth and Stahre, 2010)

\subsection{Types of allocation}

In 2008 Frohm (Frohm et al., 2008) proposed a taxonomy and definition for levels of automation used in manufacturing systems, i.e. "The allocation of physical and cognitive tasks between humans and technology, described as a continuum ranging from totally manual to totally automatic”. The taxonomy is a seven-step reference scale, for cognitive and physical LoA aiming at quantifying tasks due to LoA. Frohm (Frohm et al., 2008) defined physical tasks as the level of automation for mechanical activities, mechanical LoA, while the level of cognitive tasks is called information LoA. The taxonomy was then further developed is defined as (Fasth, 2012):

- Physical automation is defined as: "technical solutions, helping the operator to assembly the products e.g. WITH WHAT to assemble".

- Cognitive automation is defined as: "technical solutions, helping the operator e.g. HOW to assemble (Levels 1-4) and situation control (Levels 5-7)".

- Levels of Automation is defined as:" the allocation of physical and cognitive tasks between resources (humans and technology), described as discrete steps from 1 (totally manual) to 7 (totally automatic), forming a 7 by 7 LoA matrix containing 49 possible types of solutions" illustrated in fig. 2.
The figure also displays the division between human and machine assembling and monitoring the tasks.

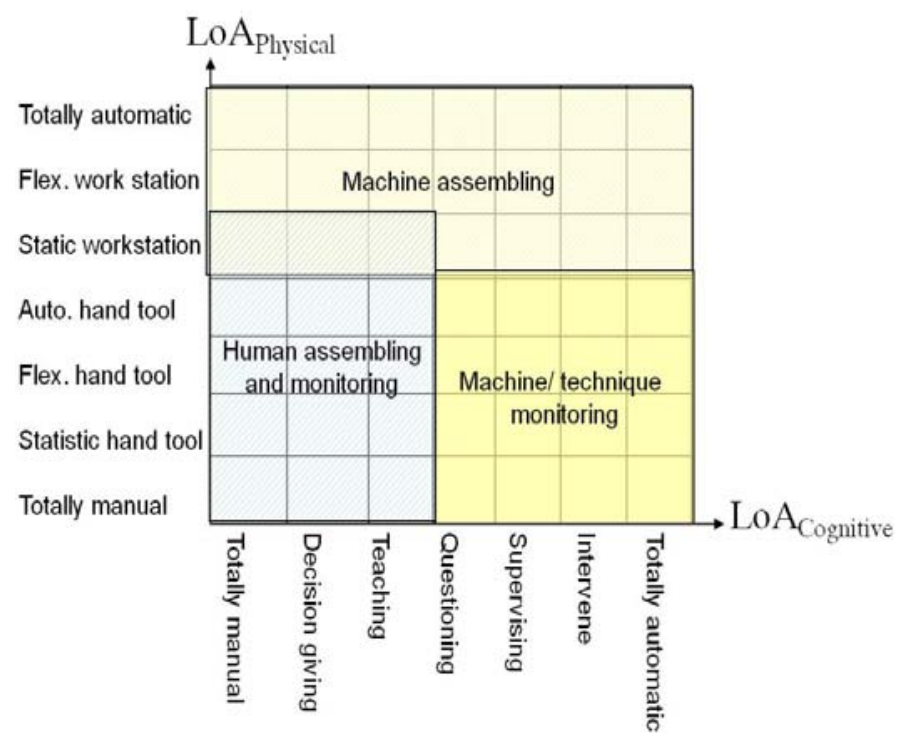

Fig. 2. Joint matrix of physical and cognitive LoA (Fasth et al., 2009 ) adopted from Frohm's taxonomy (2008)

The matrix is used as a quantitative way of measuring the current LoA in the chosen areas' tasks. The result is used for further analysis to meet triggers for change and also to make the company understand their mind set in a clearer and more 
objective way when it comes to automation. In line with Waterson and Older's types of allocation requirements; (IV) the matrix covers allocation to the humans and to the machine.

The concept model uses a mix between Sheridan's five operator roles; Plan, Teach (programming), Perform, Intervene, and Learn (Sheridan, 1992) and the work tasks in the automatic assembly system (Stahre, 1995), seen in table 1 , to be able to cover the requirements; (V) Cover allocations between humans, and examine human role and (XI) Incorporate the concept of dynamic allocations dependent on real time unforeseen even and also the issue requirement (VIII) Examine the content and quality of the human's job.

The operators' role is treated under Level of Competence (LoC) when considering task allocation. Together they form a 17-point list, used as a reference to determine the operators' action space.

Table 1 Role Allotment in production systems

\begin{tabular}{|l|}
\hline PLAN \\
\hline $\begin{array}{l}\text { Process planning and production } \\
\text { engineering }\end{array}$ \\
\hline Long time planning $(>2 \mathrm{w})$ \\
\hline Short time planning $(1-2 \mathrm{w})$ \\
\hline TEACH \\
\hline Programming for a new product \\
\hline Material handling \\
\hline Order Handling \\
\hline Set-up \\
\hline MONITOR/PERFORM \\
\hline Manual assembling \\
\hline Monitoring machines \\
\hline Maintenance \\
\hline INTERVENE \\
\hline Disturbance handling \\
\hline Lack of material \\
\hline Small disturbances \\
\hline Large disturbances \\
\hline $\begin{array}{l}\text { Quality check of product and/or } \\
\text { system }\end{array}$ \\
\hline LEARN \\
\hline Continuous improvements \\
\hline Learning new working tasks \\
\hline Teach new operators \\
\hline
\end{tabular}

These roles are then considered based on three categories, see fig. 3, if the operator has full responsibility over the task, partly responsible (together with for example the production engineer) or has no involvement at all. The result is then used for analyses of the operators 'action space' i.e. how much control does the operator have over their task allocation and is it possible for them to be proactive and use dynamic allocation (Dencker et. al, 2009).

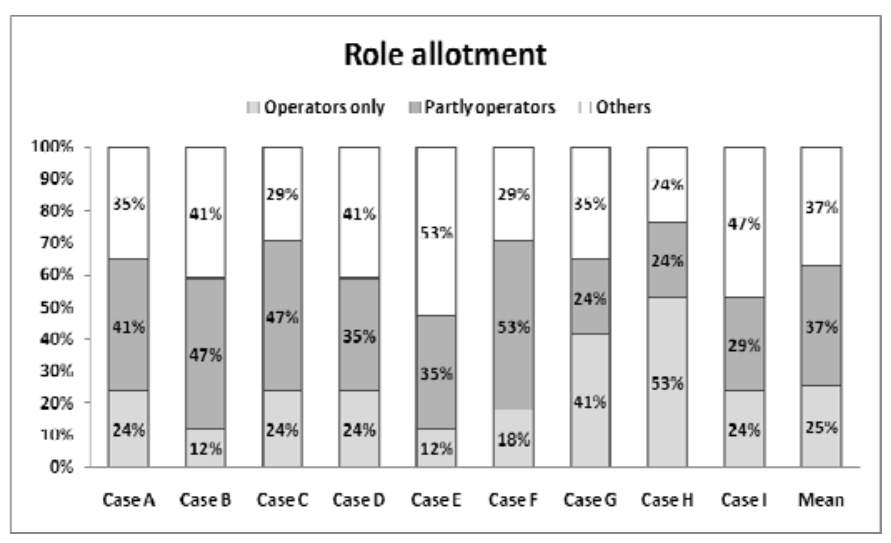

Fig. 3 Results from nine case studies

Results from the first six case studies (A-F) show that operators had the main responsibility for less than $25 \%$ of these tasks (Fasth et al., 2010) . In most companies, operators have no participation in planning and maintenance (only in small disturbance handling). Results from the case studies GI shows that within the companies who has a policy to empower their employees (cases $\mathrm{G}$ and $\mathrm{H}$ ), the responsibility were over $40 \%$ of the tasks in all companies. This puts requirements on the information flow and ICT-tools for the operators in order to handle their tasks. This is treated in the concept model as Level of Information (LoI) and the different information carriers and information content from the information system (Fässberg et. al., 2012, Karlsson et. al, 2013).

\subsection{Approach}

The methodology, DYNAMO++ (Fasth et al., 2008 -b, Fasth et al., 2010), was developed in collaboration with four companies. Furthermore, the methodology was validated in six companies (Fasth and Stahre, 2008). Validation was done to distinguish if the method could be generalised for use outside the first four companies. Further, if a novice user could understand and use the methodology. In these cases, the novice users were master students, in the discipline of mechanical engineering, with supervision of an expert. Fifteen cases in real assembly system indicate that the concept model provides industrially relevant results and increases quality of advanced, semi-automated manufacturing system analysis. Further, the validation and verification show that the concept model is easy to use for the end-users and provides quantitative data for different solutions to be compared and analysed. This is in line with two of the approach requirements; (XII) Encourage participative use by various stakeholders, including the potential end-users of the system (method) and (XII, XIII) Be easy to learn, usable and require minimal training and support

(IX) Enable the users of the method to make informed choices: According to Fasth et al (Fasth and Stahre, 2008-c) and Säfsten et al. (Säfsten and Aresu, 2000, Bellgran and Säfsten, 2005), a majority of companies studied, have a clear picture of why to change their system. However, the evaluations are often informal and unstructured, i.e. interpretation rather than facts. To choose solutions based solely on experience and interpretation rather than facts and 
numbers might not be the optimal solution when designing a system. A more reliable and objective quantitative method is therefore needed. The result from the concept models gives the users a lot of information that could be used by many different areas in a company, from the production engineers to a strategic board. Furthermore, the company get a common language when discussing LoA, in terms of the LoA matrix.

The method has only been used in already existing systems in order to make improvements, so the concept model has not been used early in the design process and is therefore either fulfilling or not fulfilling this requirement.

\subsection{Issues}

Porras and Robertsson (Porras and Robertsson, 1992) use a 2 by 2 matrix to describe changes in a structured way; Level of change (first and second degree) i.e. changes in the current system or redesigning the system and reason for change (external or internal demands). A majority of the twenty case companies wanted to do minor changes (first degree) in the current system, although two of the companies wanted to redesign the assembly system (second degree). Three of the companies were conductors and had external quality demands (these demands were achieved but required a lot of extra internal work) Therefore, they wanted to improve in-house quality and First-Time-Thru (FTT) by do minor changes in the current system i.e. internal change, first degree. The other companies wanted to either decrease time (throughput and cycle time) or increase flexibility (product or volume). The case studies done after 2010 shows an increased demand on improving the information and communication towards the operators in terms of smarter instructions, using different types of media i.e. movies, pictures and text combined (Nordin et. al, 2010, Fässberg et. al, 2010). To determine if the goals have been achieved, there is a need to divide the triggers for change into indirect measurable parameters (PIDM) and direct measurable parameters (PDM). This is in line with the requirement (VI) specify decision criteria

To be able to show the fulfilment of (VII) Consider the tradeoffs between the decisions criteria and (X) Enable quantitative evaluations to be made of the alternative choices and industrial case example will be illustrated:

Company D is an example of how companies can use LoA measurements to improve their triggers for change. According to Fasth et al (Fasth et al., 2008 -a), the company wanted to increase volume flexibility for a specific product family. A current state analysis was done, using HTA, VSM, and LoA measurement. To achieve volume flexibility the company integrated redundancy in the bottleneck station i.e two different automation alternatives could be used for assembling. The company used a manual station $\operatorname{LoA}=(3 ; 5)$ as a solution when the robot cell $\mathrm{LoA}=(6 ; 5)$ was down. In order to fulfil the incensement of volume flexibility, they could use the two stations to perform a task allocation depending on the order status on a daily basis.

The redundancy made it possible, not only to have a more robust system but to create routing flexibility and volume flexibility, thru four different alternatives to assemble the product i.e. task allocation. The amount of products produced with different alternatives is shown in fig. 4.

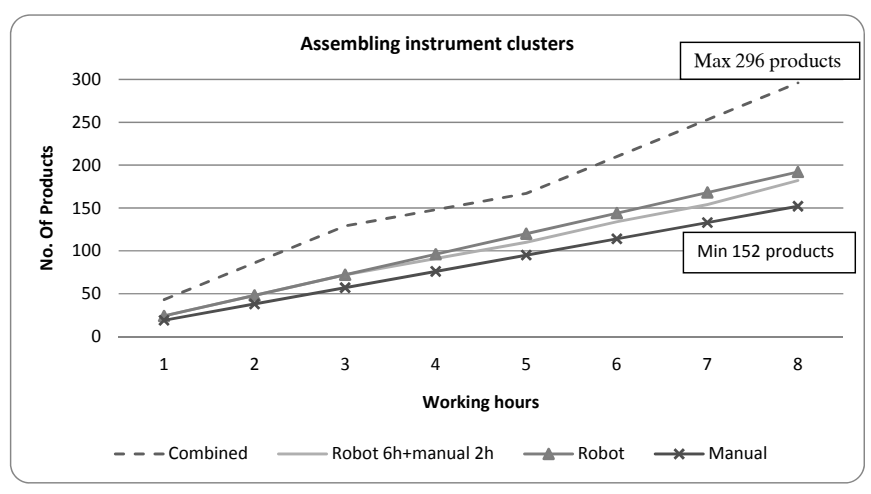

Fig. 4 creating volume flexibility through task allocation

The robot cell is used as the main machine in the system. The productivity for one normal day is 24 products/hour, i.e. 192 products per shift. Assume that a breakdown for two hours is happened in the robot cell. Without the routing flexibility the loss will be 24 parts per hour $=48$ products. With the routing flexibility the company is able to use the static work station under the reparation producing 18 products/hour i.e. a loss of 5 products per hour $=10$ products. The four alternatives give a variance of 144 (min 152, max 296) number of products. This case shows how task allocation and changing recourses could be illustrated in an easy way for the company so that they could take well-founded decisions related to the volume they wanted to produce.

\subsection{Coverage}

In order to show the adaptability of the concept model, it has been used as a whole or in modules in twenty case studies. Depending of the companies triggers for changing the system and the degree of change, different modules could be used to enlighten these areas. The participating companies come from seven different context and environments:

- Automotive (7) i.e. cars, trucks, power train, hydraulic vessels etc

- Electronics (5) i.e. instrument clusters, electronic engines

- White goods (3) i.e. heat pumps and refrigerators

- $\quad$ Smaller vehicles (2) i.e. lawn mower and fork-lifts

- Engineering manufacturing (1) i.e. machine Tool manufacturing etc

- $\quad$ Process Industry (1) i.e. pulp chemicals

- Medical equipment (1) i.e. catheters

The case studies have sometimes been performed at the same company but at different areas, for example one case study in final assembly and one in the manufacturing process step. Therefore, the concept model is fulfilling the requirements; Examine the whole system, as well as individual tasks and roles and (XIV) Be applicable to complex environments and different systems within the same environment.

\section{CONCLUSION}

The need for an easy-to-use quantitative method for task allocation has grown during the five years of development and use of the DYNAMO++ methodology and the concept model. The trend from the beginning was to focus on 
physical automation but has change to cover more of the social sustainability of the operators in terms of cognitive automation i.e. ICT-tools, improved work environment and empowering the personnel.

By showing the concept model treats Older's all requirements of a functional task allocation model we believe the this model could be used as a quantitative method in order to measure and analysing the operators environment and to allocate the best suited resource to the task.

\section{ACKNOWLEDGEMENT}

The authors want to express their deep gratitude to VINNOVA (The Swedish Governmental Agency for Innovation Systems) for funding this research in terms of the project the projects ProAct and Operator of the Future.

\section{REFERENCES}

ANNETTE, J. \& DUNCAN, K. D. (1967) Task analysis and training design. Occupational Psychology, 41, 211221.

BELLGRAN, M. \& SÄFSTEN, K. (2005) Produktionsutveckling - Utveckling och drift av produktionssystem, Lund, Sweden, Studentlitteratur.

DEKKER, S. \& WOODS, D. (2002) MABA_MABA or ABRAKADABRA? Progress on HUmanAutomation Co-ordination. Cognition, Technology and Work, 4, 240-244.

DENCKER, K., FASTH, Å., STAHRE, J., MÅRTENSSON, L., LUNDHOLM, T. \& AKILLIOGLU, H. (2009) Proactive assembly systems-realising the potential of human collaboration with automation. Annual Reviews in Control, In Press, Corrected Proof.

ENDSLEY, M. \& KIRIS, E. (1995) Out-of-the-loop performance problem and level of control in automation. HUMAN FACTORS - Human Factors and Ergonomics Society., 37, 381-394.

ENDSLEY, M. R. (1997) Level of Automation: Integrating humans and automated systems. Proceedings of the 1997 41st Annual Meeting of the Human Factors and Ergonomics Society. Part 1 (of 2), Albuquerque, NM, USA. Santa Monica, CA, USA, Human Factors and Ergonomics Society, Inc.

ENDSLEY, M. \& KABER, D. (1999) Level of automation effects on performance, situation awareness and workload in a dynamic control task. Ergonomics, 42, 462-492.

FASTH, Å. (2011) Comparing methods for redesigning, measuring and analysing Production systems. Proceedings of the 4th Swedish Production Symposium (SPS). Lund, Sweden.

FASTH, Å., STAHRE, J. \& DENCKER, K. (2008 -a) Analysing changeability and time parameters due to levels of Automation in an assembly system. Proceedings of the 18th conference on Flexible Automation and Intelligent Manufacturing - FAIM. Skövde, Sweden.
FASTH, Å., STAHRE, J. \& DENCKER, K. (2008 -b) Measuring and analysing Levels of Automation in an assembly system. Proceedings of the 41st CIRP conference on manufacturing systems Tokyo, Japan.

FASTH, Å. \& STAHRE, J. (2008-c) Does Levels of Automation need to be changed in an assembly system? - A case study. Proceedings of the 2nd Swedish Production Symposium (SPS). Stockholm, Sweden.

FASTH, Å. \& STAHRE, J. (2010-a) Concept model towards optimising Levels of Automation (LoA) in assembly systems. Proceedings of the 3rd CIRP Conference on Assembly Technologies and Systems. Trondheim, Norway.

FASTH, Å., BRUCH, J., DENCKER, K., STAHRE, J., MÅRTENSSON, L. \& LUNDHOLM, T. (2010-b) Designing proactive assembly systems (ProAct) Criteria and interaction between automation, information, and competence Asian International Journal of Science and Technology in production and manufacturing engineering (AIJSTPME), 2 (4), $1-13$.

FITTS, P. (1951) Human engineering for an effective air navigation and traffic control system. Columbus, $\mathrm{OH}$, Ohio state university.

FROHM, J., LINDSTRÖM, V., WINROTH, M. \& STAHRE, J. (2008) Levels of Automation in Manufacturing. Ergonomia IJE\&HF, 30:3.

FÄSSBERG, T., FASTH, A. \& STAHRE, J. (2012) Classification of carrier and content of information. 4th CIRP Conference on Assembly Technologies and Systems (CATS). Ann Arbor, USA.

FÄSSBERG, T., NORDIN, G., FASTH, Å. \& STAHRE, J. (2010) iPod Touch - an ICT tool for assembly operators in factories of the future? . Proceedings of the 43rd CIRP International Conference On Manufacturing Systems (ICMS). Vienna, Austria.

HANCOCK, H. A. \& CHIGNELL, M. H. (1992) Adaptive allocation by intellegent interfaces.

HOLLNAGEL, E. (2003) The role of Automation in joint cognitive systems. IFAC.

HOU, T., LIN, L. \& DRURY, C. G. (1993) An emperical studyof hybrid inspection system and allocation of inspection functions. Internetional journal of human factors in manufacturing systems, 351-367.

JORDAN, N. (1963) Allocation of functions between human and machine in automted systems. Journal of applied psychology, 47, 161-165.

KARLSSON, M., MATTSSON, S., FASTH-BERGLUND, A. \& STAHRE, J. (2013 (submitted)) Could the use of ICT tools be the answer for increasing competetiveness in swedish industry? 12th IFAC/IFIP/IFORS/IEA Symposium on Analysis, Design, and Evaluation of Human-Machine Systems. Las Vegas Nevada, USA.

KANTOWITZ, B. H. \& SORKIN, R. D. (1987) Handbook of human factors. Ch 3.3 Allocation of functions, New York, Wiley. 
LIKER, J. K. (2004) The Toyota Way: 14 Management Principles from the World's Greatest Manufacturer p. 303, USA, McGraw-Hill.

MARCH, R. \& MANNARI, H. (1981) Technology and size as determinants of the organizational structure of japanese factories. Administrative science quarterly, 26, 33-57.

NORDIN, G., FÄSSBERG, T., FASTH, Å. \& STAHRE, J. (2010) iPod Touch - an ICT tool for assembly operators in factories of the future? - Technical solutions and requirements. 3rd CIRP Conference on Assembly Technologies and Systems (CATS). Trondheim, Norway.

OLDER, M. T., WATERSON, P. E. \& CLEGG, C. W. (1997) A critical assessment of task allocation methods and their applicability. Ergonomics, 40, 151-171.

PARASURAMAN, R., SHERIDAN, T. B. \& WICKENS, C. D. (2000) A model for types and levels of human interaction with automation. IEEE transactions on system, man, and cybernetics - Part A: Systems and humans, 30, 286-296.

PARASURAMAN, R. \& WICKENS, C. D. (2008) Humans: Still Vital After All These Years of Automation. Golden anniversity special issue of Human Factors, 50, 511-520.

PORRAS, J. I. \& ROBERTSSON, P. J. (1992) Organizational Development: Theory, Practice and Research in Handbook of industrial and organisational psycology, California, Consulting Psychologist Press inc.

PRINCE, H. (1985) The allocation of function in systems. Human Factors, 27, 33-45.

SHERIDAN, T. B. (1992) Telerobotics, automation and human supervisory control, Cambridge Massachussetts, MIT Press.

SHERIDAN, T. B. (1995) Human centred automation: oxymoron or common sense? Intelligent Systems for the 21st Century, IEEE international. Proceedings of: Systems,Man and Cybernetics.

SHERIDAN, T. B. (2000) Function allocation: algorithm, alchemy or apostasy? International Journal of Human-Computer Studies, 52, 203-216.

STANTON, N. A., SALMON, P. M., WALKER, G. H., BABER, C. \& JENKINS, D. P. (2005) Human Factors Methods - A Practical Guide for Engineering and Design, Ashgate.

STAHRE, J. (1995) Evaluating human/machine interaction problems in advanced manufacturing. Computer Integrated Manufacturing Systems, 8, 143-150.

SÄFSTEN, K. \& ARESU, E. (2000) Vad är bra monteringssystem?: En studie av utvärdering och utformning på 15 industriföretag i Sverige. Linköping, Linköpings universitet.

WATERSON, P. E., GRAY, M. T. O. \& CLEGG, C. W. (2002) A sociotechnical method for designing work systems. Human Factors 44, 376. 